\section{Listening to Stories: Narrative Medicine in Internal Medicine Practice}

By Małgorzata J.M. Nowaczyk, and James D. Douketis Submitted:

\author{
July 18, 2018. Published: August 31, 2019. DOI: 10.22374/ \\ cjgim.v14i2.383
}

Our lives are lived in stories and, to make sense of our lives, we tell stories. For these stories to serve their purpose, they need to be heard. Our patients bring their stories to us and it behooves us to pay attention. Patient stories that are the subject and the object of narrative medicine. Internal medicine is a specialty of narratives: during illness, patients are forced to rewrite stories of their lives, and as physicians we are privileged in that these stories are bestowed upon us freely. Narrative medicine has developed as a response to an increasingly technology-based practice of medicine that is diverting attention from the patient to the screens of the desktop computer, tablet, or phone. Its main purpose is teaching physicians how to listen, and, once that is accomplished, to act on the stories we hear.

Over the last 30 years, medicine has undergone a significant paradigm shift as more and more people are living with their illnesses. They are no longer simply patients, rather, they are individuals who only become patients as their disease treatment or progression demands it. Patients of the past lived different stories: Stories of recovery, of successful surgeries, of getting better and leaving the patient role behind, of death and dealing with its approach. Nowadays, we care for people surviving cancer, people with chronic illness, those living with mental illness, the disabled, and those with implanted devices. These stories need to be heard.

Increasingly, medical professionals recognize that there is a lot more to the illness story than the medical narrative. Ill persons speak with a voice that is their own and not that of their doctor; they are the experts of their own illness. Narrative medicine attends to the person's situation as it unfolds not only in the context of the clinic or hospital, but of that person's whole life.

The goal of narrative medicine is to understand and honour the life stories of ill persons. Defined as "medicine practiced with the narrative competence to recognize, absorb, interpret and be moved by the stories of illness," ${ }^{1}$ narrative medicine can also be viewed as "a medicine practiced by someone who knows what to do with stories."1 Narrative medicine as practiced in the clinical setting comprises three distinct but intertwined elements: attention, representation, and affiliation. ${ }^{1}$ In practice, narrative medicine strives to achieve a balance between the patient's story and the doctor's story and to arrive at a common story that represents them both well. ${ }^{2}$

A clinical encounter begins with attention to the other person; our care begins by listening to the patient telling his story. We attend to the patient's words, phrases, body language, pauses, and silences. We pay attention to his appearance, behaviour and pattern of speech. It is this discourse, what happens between two people, that becomes the focus of the attention of narrative medicine. An engaged physician is able to hear and to answer the call of a person needing help. An attuned physician takes the stance of an eager tyro who greedily learns from the patient all there is to know about her in order to understand what the patient's needs and wishes are. Attention is the starting point of caring for another, of learning how to help and how to witness another's suffering. In the process the physician also learns about himself or herself.

In modern medicine, representation takes the form of a chart note, a consultation letter, or a direct note to the patient but in narrative medicine it can take the form of non-medical writing about the patient encounter. This type of writing allows for understanding of the patient encounter well beyond the confines of modern medicine. Reflective writing on clinical encounters allows for the discovery of aspects of the interaction that might otherwise escape recognition. Before writing occurs, the physician and the patient are separate entities but by the act of writing they can enter into a meaningful dialogue with each other. While writing non-medically, the physician often discovers aspects of himself or herself in the context of that particular encounter, aspects that may have remained hidden otherwise.

The ultimate goal of the exchange of attention and representation is affiliation - a more robust and lively mutual understanding, a better contact of minds and purposes for the patient's benefit. ${ }^{1}$ When we understand our patients' needs we are more likely to champion them as our own, to act on the patients' behalf, to represent their requests and desires to others, to advocate for them - all ultimately resulting in better overall medical care.

The training of medicine, in a bygone era, was anchored first on the humanities - philosophy, history and classical literature followed by the study of sciences: intent being the maintaining of our link to our humanity and to the human condition as whole. In the $21^{\text {st }}$ century, narrative medicine offers a vehicle that, no matter how busy and technologically-dependent we think we are, aims to maintain the humanity of the practice of medicine. Take just a few moments, literally, to listen, to reflect, and to think.

\section{References}

1. Charon R. Attention, representation, and affiliation." In: Narrative Medicine. Honouring the Stories of Illness. Oxford, New York: Oxford University Press; 2006.

2. Nowaczyk MJM. Narrative medicine in clinical genetics practice. Am J Med Genet 2012;158A:1941-7.

Małgorzata J.M. Nowaczyk, MD, MFA, FRCPC, FCCMG is with the Department of Pathology and Molecular Medicine, and of Pediatrics, McMaster University

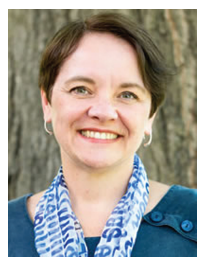

James Douketis MD, FRCPC

Editor-in-Chief, Canadian Journal of General Internal Medicine

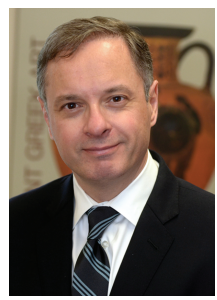

